\title{
O LANÇAMENTO DE UMA NOVA EMBALAGEM DO REFRIGERANTE COCA-COLA: UM ESTUDO DE CASO SOBRE O LANCAMENTO DA MINI PET PELA EMPRESA RIO DE JANEIRO REFRESCOS
}

THE LAUNCH OF A NEW PACKAGING REFRIGERANT COCA-COLA: A CASE STUDY ON THE LAUNCH OF THE MINI PET BY RIO DE JANEIRO REFRESCOS COMPANY

Recebido em 22.12.2014. Aprovado em 16.06.2015 Avaliado pelo sistema double blind review DOl: http://dx.doi.org/10.12712/rpca.v9i2.523

\section{Fábio Francisco de Araujo}

fabiofdearaujo@gmail.com

Pontifícia Universidade Católica do Rio de Janeiro - PUC-Rio, Rio de Janeiro/RJ, Brasil

Fundação de Apoio à Escola Técnica - FAETEC, Rio de Janeiro/RJ, Brasil

\section{Luciana Barata Adler}

lubarata@hotmail.com

Pontifícia Universidade Católica do Rio de Janeiro - PUC-Rio, Rio de Janeiro/RJ, Brasil

\section{Resumo}

Este estudo investigou o caso do lançamento da embalagem de Coca-Cola Pet 250 mililitros (ml.) realizado no Brasil pela empresa Rio de Janeiro Refrescos. O foco do lançamento recaiu sobre consumidores de baixa renda. Aaker (1998) descreve que a marca é composta por ativos e passivos que podem ser agrupados em cinco dimensões: lealdade, conhecimento, qualidade percebida. No caso dos consumidores de baixa renda, o interesse pode ser relacionado com aspirações sociais e sentimentos de inclusão, que vêm com o consumo das mesmas marcas consumidas pelas classes altas (Chauvel e Mattos, 2008). Prahalad (2005) destaca que criar ofertas competitivas para baixa renda permite aproveitar novas oportunidades de mercado. O método caso foi utilizado para condução da pesquisa (Yin, 2005). Foram realizadas entrevistas em profundidade com profissionais de marketing da empresa e de um ponto de vendas do produto, análise documental e análises dos resultados iniciais obtidos com a venda do novo produto. Os resultados mostram que a estratégica foi eficiente em enfrentar os concorrentes do mercado de bebidas não alcoólicas, e que o produto foi adequado para atingir o público-alvo. A empresa procurou articular a qualidade da marca já experimentada e reconhecida no mercado a um preço competitivo, desenvolvendo e lançando o produto Coca-Cola Pet $250 \mathrm{ml}$., com o objetivo de fornecer aos consumidores de menor poder aquisitivo um produto Coca-Cola mais acessível.

Palavras-chave: Comportamento do Consumidor de Baixa Renda. Gestão de Novos Produtos. Precificação.

\begin{abstract}
This study investigated the case on the launch of the pack of Coke Pet 250 milliliters the undertaking Rio de Janeiro Refrescos. The focus of the launch fell on low-income consumers. Aaker (1998) describes that the mark consists of assets and liabilities that can be grouped into five dimensions: loyalty, knowledge, perceived quality. In the case of low-income consumers, the interest may be associated with social aspirations and feelings of inclusion that come with the consumption of the same brands consumed by the upper classes (Chauvel e Mattos, 2008). Prahalad (2005) describes that create competitive offers for low income allows seize new market opportunities. The case study method was used to conduct the research (Yin, 2005). In-depth interviews were conducted with professional marketing company and a point of product sales, document analysis and analysis of the initial results from the sale of the new product. The results show that the strategy was effective in facing the competition of non-alcoholic beverages market, and that the product was suitable for reaching the new target, as it allowed the consumption of soft drinks Coca-Cola at a more affordable price. The company articulates the quality of the brand in the market at a competitive price, and develops and launches the product Coca -Cola Pet $250 \mathrm{ml}$, in order to provide to low-income consumer more purchasing power.
\end{abstract}

Keywords: Low Income Consumer Behavior. New Product Launch. Pricing. 


\section{Introdução}

A importância do consumidor de baixa renda começa a ser percebido tanto pelo meio acadêmico quanto pelas empresas a partir da década de 1990 (Araujo et al., 2013; Barros \& Rocha, 2007; Castilhos, 2007). No Brasil, as políticas de combate à inflação, com destaque para implementação do Plano Real, permitiram uma significativa ascensão da população das classes mais baixa e resultou no chamado consumir emergente, fato que trouxe um profundo impacto no mercado de consumo do país (Duailibi \& Borsato, 2008; Friedlander et al., 2008).

Apesar dos consumidores de baixa renda serem maioria no Brasil e no mundo, os estudos desenvolvidos sobre o comportamento do consumidor de baixa renda ainda são muito poucos (Mattoso \& Rocha, 2005), uma vez que as empresas tendem a se concentrar seu olhar no comportamento de consumo das camadas mais altas da população. Tal opção pode incorrer no risco de generalização indevida no que diz respeito às interpretações dos hábitos de consumo, tendo em vista que os resultados podem representar apenas uma fatia muito pequena da população e certamente não mostram os anseios, os desejos e os interesses da grande maioria dos consumidores.

Prahalad (2005) ressalta sobre a relevância do segmento de consumidores da base da pirâmide. Assim, as empresas devem dar maior atenção aos consumidores de baixa renda, entender seus desejos e necessidades, tendo em vista o grande contingente que esse segmento representa e consequentemente o potencial de celebração de negócios. A partir de um maior aprofundamento sobre esse segmento populacional, Prahalad (2005) sugere que sejam construídos modelos de negócios específicos voltados para esse grupo. Para o autor, essa parte da população representa um imenso e novo desafio para as empresas, pois se trata de um mercado que apresenta aspectos diversos daqueles que são mais conhecidos pelas empresas. Entretanto, estudos recentes vão mais além e apontam que em dez anos os mercados emergentes serão responsáveis por $40 \%$ do crescimento da produção mundial, e estar bem posicionado neles, portanto, é visto como uma questão de sobrevivência de longo prazo.

Em pesquisa realizada pela Fundação Getúlio Vargas do Rio de Janeiro, de 2006 para 2007 quase 20 milhões de pessoas passaram a integrar o segmento de classe média, migrando da classe $\mathrm{D}$ para classe C. Esse número é quase cinco vezes maior quando comparado com o mesmo período do ano anterior (Duailibi \& Borsato, 2008). O crescimento do potencial de compra da classe de consumidores classificados como baixa renda é explicada por meio de diferentes fatores sociais: maior salário, aumento do número de empregos, programas sociais voltados para esse segmento (como a Bolsa Família) e ofertas de créditos maiores combinados a prazos longos de pagamento e juros mais baixos. Como consequência, esse segmento se torna um forte e expressivo mercado consumidor, passando a chamar a atenção da indústria e varejistas (Duailibi \& Borsato, 2008). Com o novo potencial de compra, o consumidor de baixa renda passou a ter oportunidade de experimentar, pela primeira vez, prazeres do consumo antes restritos às classes de renda mais altas. Citamos entre eles viagens de avião, compra de eletrônicos e até mesmo mudança das marcas escolhidas para alimentação, higiene e vestuário (Barros \& Rocha, 2007; D’Andrea et al., 2003).

De outro lado, pesquisadores têm observado a tendência dos consumidores no Brasil, incluindo os consumidores de baixa renda, por marcas mais tradicionais, o que pode nos ajudar a inferir que os consumidores brasileiros podem estarmaisinteressados na percepção de qualidade e garantia de satisfação. Um exemplo dessa tendência é o comportamento de consumo dos brasileiros em relação ao mercado de bebidas. Uma pesquisa do IBGE marca a virada para essa tendência no mercado de bebidas no Brasil nas classes de consumo mais populares a partir de 2010, quando um estudo sobre orçamentos apresentou um aumento das quantidades per capita médias entre 20022003 e 2008-2009 estão produtos no mercado de bebidas nos itens de consumo não essenciais, como o refrigerante de cola (aumento de 39,3\%) e a cerveja (aumento de 23,2\%). (IBGE, 2010).

Diante dessa realidade local e considerando a oportunidade de aumentar sua rentabilidade e participação de mercado dos consumidores de baixa renda, a empresa Rio de Janeiro Refrescos, que representa a Companhia Coca-Cola nos estados do Rio de Janeiro e Espírito Santo, desenvolveu e lançou uma embalagem específica para os consumidores de baixa renda. A empresa lançou no mercado a CocaCola mini Pet, refrigerante de garrafa de plástico de $250 \mathrm{ml}$. a preço sugerido ao consumidor de $\mathrm{R} \$ 1,00$.

Nesse contexto,oestudobuscouinvestigara experiência de lançamento desse novo produto da marca Coca- 
Cola pela empresa Rio de Janeiro Refrescos (RJR), que, inicialmente, foi direcionado aos consumidores da base da pirâmide. A pesquisa procurou entender as razões estratégicas dessa escolha, bem como conhecer o impacto do lançamento desse novo produto para a empresa e varejistas. Assim, pretende-se com esse estudo poder avançar no conhecimento sobre os consumidores de baixa renda, destacar a pertinência do tema e identificar pistas para novas pesquisas.

\section{Referencial Teórico}

\section{0 consumo na base da pirâmide}

Segundo pesquisa publicada por Chauvel e Mattos em 2008 nos Cadernos Ebape, cerca de três quartos das famílias brasileiras pertencem às classes $C, D$ ou E, que respondem por $42 \%$ do consumo no país e movimentam, por ano, cerca de 390 bilhões de reais. Barros (2006) aponta que os consumidores que compõem a população de baixa renda brasileira possuem um desejo latente de inserção na chamada "sociedade de consumo", desejando participar e aproveitar dos benefícios potenciais que essa sociedade de consumo pode lhes trazer. Nesse contexto, Prahalad e Lieberthal (2003) sublinham que esses consumidores representam uma excelente chance de expansão do setor privado, tanto em relação ao consumo quanto em relação à criação de produtos ou serviços adequados para esse segmento, abordando-os com uma visão inovadora e adequada a sua realidade socioeconômica.

Barbosa et al. (2009) destacam que os consumidores de classes mais baixas tendem a optar por marcas mais tradicionais, evitando as mais baratas. A preferência por marcas tradicionais mostra que os consumidores da base da pirâmide podem estar mais interessados na percepção de qualidade e garantia de satisfação. Tal fenômeno ocorre porque esses consumidores sentem não poder "errar" na escolha da marca, pois a aquisição de uma marca que não traga o resultado esperado significa frustração, já que com o orçamento apertado não terá condições de fazer nova compra do item de diferente marca tão rapidamente (Anderson, 2002).

Prahalad (2005) destaca que os pobres são consumidores muito conscientes de marca e de valor, por motivo de necessidade. Segundo Aaker (1998), a marca de um produto é composta por ativos e passivos que podem ser agrupados em cinco dimensões, são elas: lealdade à marca, conhecimento da marca, qualidade percebida, associações à marca em acréscimo à qualidade percebida, e outros ativos do proprietário da marca. Para Brakus et al. (2009), a preferência de consumidores por determinadas marcas também pode ser relacionada a experiências positivas com a marca, que remetam à sensação de prazer. No caso dos consumidores de baixa renda, a consciência e o interesse, por mais que expressem desejar qualidade, podem também ser relacionados com aspirações sociais e sentimentos de inclusão, que vêm com o consumo das mesmas marcas que consumidores das classes mais altas (Araujo et al., 2013; Araujo \& Chauvel, 2012; Barbosa et al., 2009; Chauvel \& Mattos, 2008; Oths et al., 2003; Rocha \& Silva, 2008).

Um estudo de mercado realizado pela equipe de marketing da Rede Bahia de Televisão (2005) menciona a pesquisa realizada pela consultoria $\mathrm{BoOz}$ Allen junto a consumidores de baixa renda no Brasil, a qual constatou que esse grupo de consumidores demonstra maior racionalidade nas compras. Ao contrário do que muitos podem pensar, tal pesquisa mostrou que esses consumidores não têm interesse somente em baixo preço e baixo custo. As marcas líderes são objetos de desejo e adquiridas, na medida do possível, sobretudo nos alimentos. Há de enfatizar, ainda, que são os alimentos, juntamente com os bens de consumo não duráveis, os itens de compra em que as pessoas de baixa renda empregam grande parte de sua remuneração mensal ( $43 \%$ de sua renda). Oths et al. (2003) observaram que as pessoas inseridas nas camadas mais populares utilizam as escolhas dos alimentos como forma de mobilidade social, pois de acordo com o prestígio dos alimentos junto às classes sociais mais abastardas, eles são culturalmente desejados e, oportunamente, consumidos pelos mais pobres, que entendem este comportamento como uma maneira de aceitação e ascensão social.

Para D' Andrea et al. (2003), o desejo pelo consumo da população de classes mais baixas não se verifica apenas na compra de produtos imprescindíveis, mas também na compra de produtos das chamadas categorias "aspiracionais" e até de "luxo". Para os pesquisadores, entre os produtos das categorias "aspiracionais", destacam-se xampu, frios, cerveja, cinema, lazer em geral, entre outros; e entre os de "luxo" destacam-se os produtos supérfluos em geral, tais como leite condensado, determinados tipos de roupa, biscoito recheado, maquiagem etc.

Dessa forma, comose vê, a ideia de que os consumidores de baixa renda possuem necessidades simples é 
um mito. O desejo por consumo de marca líderes também alcança as pessoas inseridas nas camadas mais populares. Isso indica que, independentemente da posição social, a população de baixa renda aspira sim por consumo de bens e serviços de qualidade.

Nesse sentido, o crescimento e a expressividade das classes C e D passaram a se tornar uma excelente oportunidade para empresas que buscavam alternativas de crescimento, uma vez que o consumo das classes A e B se aproximavam da saturação, conforme divulgado em pesquisa realizada pela empresa de consultoria americana Boston Consulting Group (BCG) (Barreto \& Bochi, 2002). As empresas que atuam no mercado brasileiro começam a reconhecer o potencial do mercado desses consumidores, ávidos por consumir produtos de alta qualidade a preços compatíveis a seu orçamento. O grande desafio dessas empresas está em justamente tornar acessíveis seus produtos para esse mercado de menor poder aquisitivo.

\section{Características do consumidor de baixa renda}

O campo de pesquisa que pretende compreender os hábitos de consumo dos consumidores inseridos nas classes inferiores brasileiras, segundo Mattoso e Rocha (2005), ainda está longe da saturação. Descobrir quais as condições para se desenhar uma oferta competitiva para os consumidores de baixa renda e como aproveitar este segmento para novas oportunidades no mercado de consumo pode significar vantagem competitiva às empresas (D’Andrea, 2004).

Silva e Parente (2007) observam que o segmento de baixa renda no Brasil não pode ser considerado como homogêneo. Os autores identificam cinco perfis distintos a partir dos gastos familiares. O primeiro perfil retrata os "sofredores de aluguel", consumidores que vivem em moradia alugada e têm o orçamento comprometido com esse item, tendo um alto nível de inadimplência. $O$ segundo perfil analisado é o "jeitinho brasileiro", consumidores que utilizam de formas alternativas para cobrir o orçamento mensal, tendo dificuldades de cumpri-lo devido suas grandes restrições orçamentárias. O terceiro perfil se refere a "valorização do ter", representados pelos consumidores que fazem parte de famílias maiores e com índices mais elevados de escolaridade, apresentando um consumo maior de bens duráveis. O quarto perfil diz respeito aos "batalhadores pela sobrevivência", os consumidores inseridos em famílias em que os chefes são mais idosos e com um maior índice de analfabetismo. O quinto e último grupo analisado são os "investidores", consumidores que aplicam parcela substancial de seus recursos em ativos ou investimentos financeiros.

Entretanto, há autores que propõem uma análise do perfil consumidor de baixa renda a partir do seu comportamento de compra. Rocha e Silva (2008), citando Sachs, indicam que população de baixa renda pode ser dividida ainda de acordo com o seu grau de pobreza e suas necessidades de compra. Segundo esse critério, esses consumidores foram divididos de acordo com a seguinte classificação: extrema pobreza, em que se verifica o não atendimento das necessidades básicas de alimentação e moradia; pobreza moderada, em que apesar de as necessidades básicas serem atendidas, as necessidades secundárias, tais como saúde, educação e outras do gênero, não são sempre satisfeitas; pobreza relativa, em que a renda é inferior a média nacional, mas conseguem ter acesso as necessidades secundárias.

Prahalad (2005) sublinhou que a capacidade de compra envolve a criação de ofertas que sejam acessíveis a todas as classes. Dado o baixo poder aquisitivo dos consumidores de baixa renda, uma alternativa que vem sendo desenvolvida pelas empresas é a criação de pacotes individuais e ofertados a preços mais acessíveis. Ademais, Prahalad afirma que apesar do pouco acesso à informação, em decorrência da baixa escolaridade, esses consumidores buscam racionalidade nas escolhas, já que seus recursos financeiros são escassos.

Em relação ao consumo de crédito, observa-se que muitos desses consumidores adéquam suas compras a prestações que possam se enquadrar em seu orçamento, não sendo relevante para eles o preço final pago, mesmo se incluir juros altos (Mattoso \& Rocha, 2005). O grande impulsionador das compras dos segmentos mais baixos da sociedade é justamente a possibilidade real de pagar em várias prestações e, se possível, com taxas de juros pouco elevadas. Ponchio e Aranha (2007) trazem que a ideia de criar mecanismos de compensação de impostos a varejistas, oferecendo alternativas de crédito a taxas de juros mais baixas, o que beneficia o mercado de consumo como um todo, tendo em vista que até os indivíduos atualmente marginalizados da sociedade de consumo teriam acesso mais facilitado ao crédito.

Além do crédito, a estratégia de comunicação é um importante aspecto a ser considerado pelas empresas que pretendem atingir o público de baixa renda. $\mathrm{O}$ estudo de Kelman, Chauvel e Lopes (2005) mostra que as pessoas tendem a memorizar as ofertas e 
utilizar essa fonte de informação para comparar preços. Para Silva (2005), a população de baixa renda é muito influenciada pelos meios de comunicação dado sua busca pela inclusão social, diferentemente das classes mais altas, as quais não recebem a mesma quantidade de influência em razão de sua busca pela diferenciação. É preciso reconhecer o simbolismo que a comunicação de massa pode exercer nos grupos de consumidores inseridos na base da pirâmide.

\section{0 mercado de bebidas}

O mercado de bebidas, no Brasil, é analisado pela ACNielsen considerando dois grupos: bebidas alcoólicas e bebidas não alcoólicas. De acordo com a ACNielsen, o valor médio da cesta de consumo do brasileiro cresceu $6 \%$ no primeiro semestre do ano, sendo que as altas mais expressivas foram observadas em bebidas não alcoólicas $(9,9 \%)$, bebidas alcoólicas $(9,6 \%)$ e produtos perecíveis $(8,1 \%)$ (Nielsen Brasil, 2010).

De acordo com pesquisa realizada pelo Ibope Mídia (2008), o produto refrigerante é o mais consumido na categoria de bebidas não alcoólicas e abrange mais de 52 milhões de pessoas, seguido pelo mercado de sucos com 48 milhões de consumidores (também da categoria de bebidas não alcoólicas), e de cervejas com mais de 22 milhões de consumidores nas principais regiões metropolitanas (produto da categoria de bebidas alcoólicas). No Brasil, o volume de consumo de litros de refrigerantes é tão alto que, segundo a ABIR (Associação Brasileira das Indústrias de Refrigerantes e de Bebidas Não Alcoólicas), o país ocupa o terceiro lugar no ranking mundial do consumo de refrigerantes, com cerca 11,9 bilhões de litros consumidos por ano, atrás apenas dos EUA (57 bilhões de litros) e do México (12,7 bilhões de litros).

$O$ setor de refrigerantes no Brasil apresenta um modelo de estrutura oligopolista, visto que um número reduzido de empresas domina uma fatia considerável do mercado (Afrebras, 2011). Em fevereiro de 2006, de acordo com a ACNielsen, a família de marcas da Coca-Cola (Coca-Cola, Coca-Cola Light Plus, CocaCola Zero, Guaraná Kuat, Fanta e Sprite) detinha uma participação de 53,4\% no mercado brasileiro de refrigerantes, enquanto a Ambev detinha uma participação de $17,3 \% \mathrm{em}$ refrigerantes. Isso significa mais de $70 \%$ do volume de mercado está concentrado na mão de duas empresas. O restante do mercado é composto de empresas regionais que detém marcas como "Tobi", "Convenção" e "Pakera". O mercado de refrigerantes conhece essas marcas por “tubaínas". Pela preferência dos consumidores, as grandes empresas Coca-Cola e Ambev - conseguem ter maior poder de compra de matéria-prima, e maior poder econômico de investimento quando comparado às pequenas e médias empresas, acarretando em desigualdade no desempenho mercadológico (Afrebras, 2011). Entretanto, quando se discute concorrência no mercado de refrigerantes, é preciso compreender que o padrão de concorrência nessa indústria é baseado em diferenciação, na qual os produtos apresentam algumas distinções entre si, acarretando em diferentes graus de preferências quanto ao desejo de consumidor os produtos (Tavares, 2000).

As maiores empresas de refrigerantes presentes no mercado brasileiro são empresas multinacionais que produzem seu portfólio de produtos em larga escala, têm um forte esquema de distribuição, investem altas quantias em propaganda e marketing, além de reforçar o processo de diferenciação. A essas empresas, a principal barreira de mobilidade está justamente em investimentos em diferenciação, que no caso de bens de consumo em massa exige elevadas escalas de operação. Esses custos caracterizam barreiras à saída, uma vez que a empresa que adentra a este grupo estratégico incorre em investimentos que não são apropriáveis em outros mercados, os chamados sunkcosts (Veloso, 2004).

A barreira de entrada encontrada pelas empresas de refrigerantes regionais, devido ao grande número de empresas que possuem reduzida parcela do mercado, está na logística de distribuição. Faz-se necessária capacidade de articulação com a rede de distribuição para levar os produtos aos pontos de venda, o que exige altos investimentos por parte desse grupo. Essa indústria é também caracterizada por alta elasticidade, o que impacta diretamente no preço. A existência de inúmeros bens substitutos e a não essencialidade do refrigerante à população explica tamanha sensibilidade dos consumidores a alterações de preços (Afrebras, 2011; Veloso, 2004). Tavares (2000) observa que o preço é uma questão que deve ser considerada para despertar o interesse de compra dos consumidores de baixa renda, sugerindo a estratégia de diferenciação por preço como adequada para o segmento. Além disso, é preciso considerar que as empresas de refrigerantes concorrem com vários produtos oferecidos pelo mercado de bebidas não alcoólicas. Nesse sentido, é válido mencionar o que informa Keller et al. (2002):

"A Coca-Cola compete com a Pepsi, entre outros refrigerantes. Há circunstâncias, porém, em que o padrão de referência será 
constituído por marcas de diferentes categorias. Coca-Cola, Gatorade e Snapple pertencem à categoria de refrigerantes, das bebidas esportivas e dos chás gelados, respectivamente. Mas compartilham potencialmente de uma estrutura de referência que compreendem todas as bebidas que saciam a sede" (Keller et al., 2002, p. 95).

Nesse sentido, além dos próprios refrigerantes, as empresas de refrigerantes precisam concorrer com outros segmentos de produtos da indústria de bebidas não alcoólicas, tais como água, sucos, refrescos, chás, água de coco etc.

Vale destacar que um produto que tem crescido muito no mercado de bebidas não alcoólicas é o chamado "guaracopo". O guaracopo é o nome popular das diversas marcas de chás e guaraná natural não carbonatados. Para a ACNielsen, os guaracopos não são auditados na categoria de refrigerantes, mas na categoria de chás prontos. Dados de 2009 mostraram que 60 milhões de litros de chás prontos foram consumidos no Brasil, com taxa de crescimento de mercado de $12 \%$. Destes 60 milhões de litros, 10\% foram tomados pelos guaracopos (Nielsen Brasil, 2010). Segundo Paulo Furquim de Azevedo (2008), conselheiro do Conselho Administrativo de Defesa Econômica (CADE), o mercado de guaraná natural está concentrado no Rio de Janeiro, onde ocorrem $73 \%$ das vendas de guaracopos.

\section{Metodologia}

Este estudo teve como objetivo investigar o impacto do lançamento de um novo produto da marca CocaCola pela empresa Rio de Janeiro Refrescos (RJR), a partir da criação de uma nova embalagem para o refrigerante, pensada para alcançar os consumidores de baixa renda. Para atingir o objetivo proposto, procurou-se reunir elementos para descrever da melhor forma possível esse processo, adotando uma perspectiva interpretativista (Brown, 1997).

A empresa Rio de Janeiro Refrescos é a engarrafadora e distribuidora dos produtos Coca-Cola para os estados do Rio de Janeiro e Espírito Santo. Nessas regiões, a empresa é líder de participação de mercado na categoria refrigerante (Coca-Cola Brasil, 2014).

O método caso foi utilizado para condução do presente estudo. Esse método é adequado para investigar em profundidade um fenômeno contemporâneo no seu contexto real (Yin, 2005). De acordo com Yin (2005), o estudo de caso é um método flexível, permitindo utilizar conjuntamente várias fontes de evidências, o que se mostrou necessário para o estudo. Além disso, Mattar (1997) afirma que esse método permite aprofundar o conhecimento de problemas sobre os quais se dispõe de poucos elementos, o que representou uma importante vantagem para esta pesquisa. A adoção dessa metodologia, que preconiza o uso de múltiplas fontes de evidência, cria condições para uma triangulação dos dados durante a fase de análise (Yin, 2005). Foram utilizados como fontes (i) investigação documental, (ii) dados arquivados, (iii) artefatos físicos, (iv) observação direta dos autores, (v) e entrevistas em profundidade. Os dados coletados foram tratados de forma qualitativa.

A entrevista qualitativa em profundidade é um método amplamente utilizado (Gaskell, 2002) e, segundo McCracken (1988), a conversa direta e pessoal facilita ao pesquisador captar o universo mental do entrevistado. As entrevistas em profundidade deste estudo foram realizadas com profissionais de marketing da empresa Rio de Janeiro Refrescos (RJR) que participaram da concepção e lançamento da embalagem, a saber: a gerente de marketing dos canais de distribuição e a analista de marketing que liderou o projeto de lançamento da embalagem. Além dessas, foi realizada uma entrevista em profundidade com um gerente de minimercado situado na cidade do Rio de Janeiro, que atende ao público de baixa renda e que foi selecionado para trabalhar com o novo produto na época de seu lançamento. Esta última entrevista procurou obter pistas sobre o impacto do produto no ponto de venda. As entrevistas tiveram duração de aproximadamente 40 minutos cada e foram integralmente gravadas e transcritas para análise. Para cada uma delas, foi elaborado um roteiro que abordava os tópicos pertinentes a cada entrevistado. Concomitantemente à gravação, foram realizadas observações e anotações dos pesquisadores, que geraram um diário de campo. Os dados colhidos foram analisados conjuntamente, buscando compreender e descrever o mercado potencial vislumbrado pela empresa e o resultado do lançamento deste novo produto. Em razão do caráter exploratório do presente estudo de caso, os resultados dessa pesquisa não podem ser generalizados. Buscouse, com esse artigo, apresentar contribuições para o avanço do conhecimento sobre o mercado de baixa renda a partir de uma ação estratégia de uma empresa direcionada para esse segmento.

\section{Resultados}

Esta seção encontra-se organizada da seguinte forma: primeiro, é apresentada uma breve contextualização 
sobre a empresa Rio de Janeiro Refrescos (RJR); segundo, são trazidas algumas informações sobre o mercado de refrigerante Coca-Cola; terceiro, são discutidas os principais achados sobre o lançamento do produto Coca-Cola na embalagem de 250 mililitros (ml.); por último, são discutidos os impactos identificados no lançamento do novo produto.

\section{A empresa Rio de Janeiro Refrescos (RJR)}

O sistema Coca-Cola Brasil é composto pela CocaCola Brasil e 16 grupos independentes, chamados de fabricantes autorizados, somando-se ainda as empresas Leão Junior e Del Valle. Cada empresa do grupo elabora o produto final em suas 46 unidades industriais e os distribuem aos pontos de venda. Os fabricantes têm um contrato por meio do qual se comprometem a produzir, engarrafar e distribuir todos os produtos da Coca-Cola Brasil (Coca-Cola Brasil, 2014).

A empresa Rio de Janeiro Refrescos (RJR) foi a primeira fábrica da Coca-Cola no Brasil, e atualmente é uma integrante desse grupo de fabricantes autorizados. Fundada em 1942, desde 1994 integra o Grupo Andina, maior fabricante Coca-Cola no Chile e com operações também na Argentina (RJR, 2014).

No Brasil, a Rio de Janeiro Refrescos é responsável pela produção e distribuição dos produtos do portfólio da Coca-Cola nos estados do Rio de Janeiro (excluindo a região sul-fluminense, região esta atendida por outra franquia do sistema Coca-Cola) e Espírito Santo. A RJR possui duas fábricas, sendo uma localizada no bairro de Jacarepaguá, cidade do Rio de Janeiro, e a outra na cidade de Vila Velha no Espírito Santo (RJR, 2014).

Segundo informação divulgada no site da empresa, a missão da empresa Rio de Janeiro Refrescos é "liderar o mercado de bebidas, sendo reconbecida como a melhor empresa para se investir e trabalhar, superando as expectativas dos clientes e consumidores, colaborando para o desenvolvimento da qualidade de vida da nossa sociedade" (RJR, 2014).

Existem na fábrica do Rio de Janeiro, nove linhas de produção, enquanto na fábrica do Espírito Santo são três linhas dedicadas a fabricação de refrigerantes. A Rio de Janeiro Refrescos é líder de mercado nas áreas em que fornece refrigerante ao mercado consumidor.

A empresa (RJR) tem aproximadamente 51\% de market share no mercado de refrigerantes nas áreas onde atua em todos os canais de distribuição (Gerente de Marketing, RJR).

[...] na região do Grande Rio, por exemplo, ela [a RJR] chega a ter até mais de $70 \%$ de market share (Analista de Marketing, RJR).

O principal canal de comunicação entre a empresa e o varejista é feita por meio do representante comercial, conhecido como no mercado como "vendedor". O representante comercial é o profissional que tem como principal função vender o portfólio de produtos da Coca-Cola para o varejista, de acordo com as recomendações estratégias da empresa.

O vendedor [representante comercial] visita o ponto de venda de uma a seis vezes por semana, dependendo do tamanho e importância do ponto de venda. Além de tirar o próximo pedido e repor o estoque, ele apresenta as promoções, os lançamentos, informa se tem algum produto em falta; ele faz toda a comunicação da empresa para com o cliente [...] a entrega é feita normalmente no dia seguinte (Gerente de Marketing, RJR).

O mercado tem uma relação boa com o vendedor [representante comercial]. Geralmente os vendedores vêm aqui, expõem, explicam porque tem o produto novo no mercado, preço e explicam o motivo pelo qual eles [a empresa] lançaram esse produto [...] o vendedor vem aqui duas vezes por semana (Gerente de um minimercado no Rio de Janeiro).

A visão do sistema Coca-Cola, que deve ser seguida por todos os 16 fabricantes autorizados, foi definida por Augusto César Parada, presidente da Vonpar Fabricante autorizada responsável pelo atendimento dos estados do Rio Grande do Sul e Santa Catarina. Em entrevista concedida ao jornal "A Notícia", publicada no portal Clic RBS em julho de 2009, Parada colocou que "o produto Coca-Cola tem na sua visão atender a todas as classes sociais. É um produto de consumo de massa".

Apesar da empresa [RJR] ter sua estratégia de atuação muito bem dividida por marca, embalagem e canal, acredito que o maior target da empresa - pelo menos na grande maioria das marcas e tamanhos - é sempre a mãe de classe média (Gerente de Marketing da RJR).

A visão da profissional de marketing da empresa RJR, que afirma que recentemente o foco da empresa voltou-se para tentar criar estratégias para alcançar também o público das classes mais populares, está alinhado à importância que os consumidores das classes $\mathrm{C}$ e D vêm recebendo do mercado nos últimos anos. Nesse contexto, visando alcançar também esse público-alvo, segundo a gerente de marketing (entrevista aos autores) começou-se a pensar em uma embalagem do produto Coca-Cola a um preço mais acessível.

A visão apresentada pela gerente de marketing da RJR encontrar amparo na recente literatura que vem se desenvolvendo sobre esse segmento de consumidores. 
Segundo Giovinazzo e Wrigth (2004), é fundamental que as empresas brasileiras, dos variados setores do mercado, reconheçam o potencial e saibam aproveitar as oportunidades advindas de um posicionamento estratégico adequado para um enorme número de consumidores de baixa renda, ávidos por adquirir produtos de qualidade e com preços compatíveis ao seu poder aquisitivo.

\section{0 mercado de refrigerante Coca-Cola}

O produto Coca-Cola surgiu em 1886 como um sabor refrescante único em uma pequena farmácia da Atlanta. Atualmente, a Coca-Cola Company está presente em mais de 200 países e responde por mais de 400 marcas de bebidas não alcoólicas, entre elas quatro das cinco marcas mais consumidas em todo o mercado mundial, as sejam: Coca-Cola, Coca-Cola Light, Fanta e Sprite. A marca Coca-Cola é líder no mercado de refrigerantes, e a razão do sucesso da marca, na visão da empresa, está na aceitação por todos os tipos de público, sem distinção de classe social ou idade (Coca-Cola Brasil, 2014).

Segundo a analista de marketing da RJR (entrevistas aos autores), a empresa disponibiliza o refrigerante Coca-Cola e outros de seu portfólio em diferentes embalagens. Na indústria de bebidas, as embalagens são geralmente classificadas em dois tipos: retornáveis ou descartáveis. No Brasil, as descartáveis mais utilizadas são latas de alumínio, latas de aço, garrafas plásticas de politereftalato de etileno (mais conhecido como embalagem PET) e garrafas de vidro. As embalagens retornáveis por sua vez são aquelas clássicas de vidro e as garrafas plásticas retornáveis, chamadas REFPET. Essas embalagens são devolvidas pelos consumidores aos pontos de compra, retornando às linhas de produção das unidades fabris, onde são limpas e higienizadas antes de receberem novamente o produto (líquido).

Para a analista de marketing da RJR (entrevistas aos autores), cada tamanho de embalagem é considerado um produto específico, ainda que da mesma bebida. A Coca-Cola Company disponibiliza o mesmo produto em variedade de tamanhos e embalagens de forma a oferecer a seu consumidor embalagens apropriadas para as mais diversas ocasiões de consumo. A ocasião de consumo imediato ocorre principalmente em bares, restaurantes e lanchonetes, e para os consumidores que vão a esse ponto de compra para adquirir uma bebida, às embalagens mais adequadas para troca são as de menor tamanho.
Os refrigerantes vendidos para ocasiões de consumo futuro podem ser adquiridos refrigerados ou na temperatura ambiente. Os principais canais varejistas caracterizados pelo consumo futuro são os supermercados, minimercados, mercearias e padarias. Os consumidores compram o refrigerante Coca-Cola para ser consumidos posteriormente, em casa, festas ou reuniões. Nesses canais varejistas os consumidores podem comprar tanto as embalagens individuais (de menor litragem) quanto familiares (maior litragem), dependendo que quantas pessoas irão consumir o produto.

Segundo a gerente de marketing da RJR (entrevistas aos autores), o refrigerante Coca-Cola é produzido e distribuídas em 14 formatos distintos, são eles: CocaCola de $200 \mathrm{ml}$ em garrafa de vidro retornável; CocaCola de $250 \mathrm{ml}$ em embalagem lata de alumínio; CocaCola de $290 \mathrm{ml}$ em garrafa de vidro retornável; CocaCola de $350 \mathrm{ml}$ em lata de alumínio; Coca-Cola de 350 $\mathrm{ml}$ em garrafa de vidro descartável; Coca-Cola de 600 $\mathrm{ml}$ em garrafa de plástico; Coca-Cola de 1 litro em garrafa de plástico; Coca-Cola de 1,5 litros em garrafa de plástico; Coca-Cola de 1,75 litros em garrafa de plástico; Coca-Cola de 2,25 litros em garrafa de plástico; Coca-Cola de 1,25 litros em garrafa de vidro (embalagem exclusiva para o RJ); Coca-Cola de 1 litro em garrafa de vidro (embalagem exclusiva para o ES); Coca-Cola em post mix (disponíveis em copos de 200 $\mathrm{ml}, 300 \mathrm{ml}, 500 \mathrm{ml}$ e $700 \mathrm{ml}$; ; e a nova embalagem de Coca-Cola de $250 \mathrm{ml}$ em garrafa de plástico.

A analista de marketing da RJR destaca que a concorrência no mercado de refrigerantes e preço são os principais desafios enfrentados para manter o consumo do refrigerante Coca-Cola.

Um dos grandes desafios que a gente precisa enfrentar para manter o alto consumo dos refrigerantes Coca-Cola é a elasticidade no preço do produto. A concorrência no mercado de refrigerantes não é se restringe aos concorrentes diretos, mas é preciso lidar com o fato de que o consumidor pode optar por comprar um substituto no mercado de bebidas, daí as restrições quanto às estratégias de precificação do produto (Analista de Marketing da RJR).

O consumo de refrigerante pela população de baixa renda sofre impactos em razão do preço e, segundo a analista de marketing da RJR, o preço praticados nos pontos de venda do refrigerante Coca-Cola pode ser determinante para o consumidor com orçamento mais restrito opte por outra bebida no momento do consumo.

Independente de onde os consumidores estejam o preço praticando no ponto de venda pode ser determinante para a decisão do consumidor de baixa renda por um produto 
concorrente ou por um substituto. Por exemplo, no mercado, o consumidor pode está disposto a consumir refrigerante, mas se esbarra num refrigerante mais barato, estando ele com orçamento mais apertado, ele pode optar por consumir o refrigerante da concorrência, ou mesmo levar outra bebida. Aqui no Rio de Janeiro, na praia, pode acontecer do consumidor ter vontade de consumir um refrigerante Coca-Cola, mas se o preço praticado nos pontos de venda, fatalmente o consumidor opta por um produto concorrente. Daí, a necessidade de se manter um esforço de manter os nossos preços mais competitivos e na medida do possível, acessíveis ao diferentes segmentos de consumidores (Analista de Marketing da RJR).

\section{0 produto Coca-Cola Pet $250 \mathrm{ml}$.}

O produto Coca-Cola Pet $250 \mathrm{ml}$. foi lançado pela empresa RJR em 2009, visando a atender uma parcela de consumidores considerados atrativos, os consumidores de baixa renda. O foco recaía sob os compradores dos concorrentes indiretos, tais como refrescos, guaracopos e caldos de cana que, são ofertados ao consumidor por preços mais baixos.

Conforme observado na pesquisa realizada pela consultoria $\mathrm{Booz}$ Allen junto a consumidores de baixa renda brasileiros (Rede Bahia, 2005), os consumidores de menor renda não preferem somente produtos de baixo preço, mas as marcas líderes são objeto de desejo e são adquiridas esporadicamente por esse segmento. No mesmo sentido, Prahalad (2005, p. 131) ensina que "existe um conceito errado de que, por serem pobres, os consumidores de baixa renda não desejam produtos de qualidade".

A empresa RJR, por sua vez, passava por um momento de reflexão de como alcançar os segmentos mais populares de consumidores, uma vez que, como se viu, o Rio de Janeiro concentrava 80\% do consumo da venda de guaraná natural e, ainda, precisava lidar os demais concorrentes, tanto os refrigerantes quanto outras bebidas não alcoólicas. Segundo a gerente de marketing da RJR (entrevista aos autores), a empresa buscou desenvolver um produto que fosse acessível para os consumidores que desejam o refrigerante Coca-Cola, líder em seu segmento, mas cujo consumo está restrito a sua limitação orçamentária.

Segundo a analista de marketing da RJR (entrevista aos autores), observou-se que esse grupo de consumidores buscava adequar seus desejos de consumo a seu orçamento e, em razão de possuir recursos mais escassos, optavam por adquirir os substitutos de refrigerantes, em geral guaracopos, refrescos e caldos de cana; estes ofertados a preços atrativos. Percebeuse, então, existir um mercado de consumidores importantes não capturados pela RJR/Coca-Cola, por motivo de falta de opção de embalagem a preço competitivo.

A equipe de marketing mostrava-se consciente de que se, de alguma forma, os produtos concorrentes ou substitutos conseguirem se estabelecer sem nenhuma reação da empresa que atua no mercado do Rio de Janeiro, a RJR poderia sofrer queda nos lucros e também no crescimento no longo prazo. Conforme recomenda Tavares (2000), em se tratando de alcançar consumidores de baixa renda, uma estratégia a ser considerada a diferenciação por preço.

Quando perguntado à gerente de Marketing de Canais de Distribuição da RJR quais seriam os concorrentes (diretos ou indiretos) que o novo produto - Coca-Cola Pet $250 \mathrm{ml}$ - enfrentaria sua resposta foi objetiva:

Guaracopos. A ideia inicial era conquistar uma fatia de mercado na qual os produtos Coca-Cola ainda não estavam presentes (Gerente de Marketing da RJR).

A ideia da nova embalagem no formato apresentado na forma de garrafa de plástico e com litragem de $250 \mathrm{ml}$. veio da matriz do Grupo Andina, pois foi lançado no Chile um produto com embalagem nessa medida, visando atender a demanda de consumidores chilenos que desejam comprar Coca-Cola em menor quantidade. A ideia foi adaptada para a realidade do mercado consumidor brasileiro, e lançada no Brasil com objetivos diferentes.

Como existia um potencial de mercado em canais de consumo futuro ainda não atacado por nenhum dos produtos da empresa, e sabendo que a matriz do Chile já trabalhava com este artigo, como estratégia de aumento de penetração nestes canais, iniciou-se um estudo de viabilidade de produção deste item (Gerente de Marketing da RJR).

A afirmação da profissional de marketing da RJR revela que a empresa identificou um nicho de mercado potencial. Com base na oportunidade vislumbrada, procurou-se um formato de embalagem que pudesse capturar esse consumidor que efetuava suas compras nos chamados canais de consumo futuro (supermercados e minimercados). Tendo em vista que as empresa desejava alcançar os consumidores de baixa renda, era preciso também considerar a princípio apenas os canais de distribuição que atendiam esse segmento, observando se esses canais iriam efetivamente revender o produto com a embalagem de $250 \mathrm{ml}$. com um preço de oferta acessível. Além disso, a estratégia da empresa previa disponibilizar a nova embalagem apenas nas lojas que apresentassem percentual menor que $10 \%$ em venda de embalagens individuais de refrigerante Coca-Cola (até $600 \mathrm{ml}$.). 
$\mathrm{Na}$ verdade, a gente já trava essa guerra com refrescos, caldos de cana e guaracopos há muito tempo e, a Coca-Cola não conseguia desenvolver uma embalagem que pudesse combatê-la (Analista de Marketing da RJR).

Há de se destacar, ainda, que o portfólio da empresa já contava com uma embalagem da mesma litragem, isto é, uma embalagem de $250 \mathrm{ml}$., mas no formato lata de alumínio. Essa embalagem não poderia capturar a oportunidade vislumbrada pela empresa, que seria conquistar a preferência de consumidores da base da pirâmide, por motivos operacionais e por razões de estratégia de portfólio da própria empresa.

Dentro do portfólio da Companhia já existia outro produto nesta mesma litragem, a mini lata de $250 \mathrm{ml}$., porém com crescimento restrito devido à limitação da produção da embalagem pelo fabricante de lata (Gerente de Marketing da RJR).

Existe uma embalagem de lata de $250 \mathrm{ml}$. também, mas ela está muito focada em depósitos, para abastecimento dos ambulantes. A gente tinha a preocupação de colocar essa embalagem (mini lata $250 \mathrm{ml}$ ) nos mesmos canais que trabalhavam com a lata de $350 \mathrm{ml}$ e ela [a mini lata $250 \mathrm{ml}$.] acabar por canibalizar a outra que tem uma margem muito melhor do que a de $250 \mathrm{ml}$. (Analista de Marketing da RJR).

O novo produto, a Coca-Cola Pet $250 \mathrm{ml}$., foi lançado para os canais com foco em consumo futuro, seguindo a estratégia desenhada pela empresa a preço sugerido de $R \$ 1,00$ (um real), visando competir com guaracopos e outras bebidas não alcoólicas de preços mais acessíveis.

Preços como $\mathrm{R} \$ 1,00$ e $\mathrm{R} \$ 0,99$ são considerados mágicos dentro do cenário do varejo de produtos de consumo de baixo valor [...]. Como os principais concorrentes da embalagem possuíam preços até menores do que estes, mas sabendo que por se tratar de um produto da marca Coca-Cola e até para garantir o retorno do investimento, escolheu-se este valor - R $\$ 1,00$ - para uma entrada competitiva e rentável para a Companhia nesse mercado (Gerente de Marketing da RJR).

A afirmação acima demonstra que a empresa optou por estabelecer um preço que fosse ao mesmo tempo atrativo para o consumidor, competitivo frente aos concorrentes, sem deixar de ser "Premium", por fazer parte da cartela de produtos da Coca-Cola. Tratavase, ainda, de um projeto rentável, pois, segundo a entrevistada, a intenção da empresa não estava somente em conquistar novos clientes, mas em fazêlo de maneira financeiramente viável.

Os preços menores praticados pelos concorrentes de bebidas não alcoólicas podem ser explicados pela estrutura de atendimento que as empresas regionais e canais varejistas apresentam ao ofertar guaracopos, refrescos e caldos de cana.

Competir com produtos de competidores que não têm uma carga tributária como a da Coca-Cola, que não investem em publicidade e Propaganda \& Desenvolvimento como a empresa [Coca-Cola], e que mantém preços quase que irrisórios, são as maiores dificuldades deste nicho de mercado (Gerente de Marketing da RJR).

O produto foi apresentado aos varejistas pela equipe de representantes comerciais da empresa RJR e com o apoio de materiais de comunicação. Optou-se por, antes de realizar uma promoção mais ampla do produto, observar os resultados nos pontos de venda estrategicamente escolhido para o lançamento do novo produto.

No caso dessa embalagem em particular foram desenvolvidos apenas materiais de comunicação para os pontos de venda, e foi feita uma extensa campanha de divulgação para a Força de Vendas nas matinais, equipe esta responsável em penetrar com o produto nos clientes (Gerente de Marketing de Canais de Distribuição, RJR).

A Figura 1 a seguir apresenta o novo produto do refrigerante Coca-Cola, apresentado em sua nova embalagem Pet de $250 \mathrm{ml}$.

Figura 1 - Coca-Cola na embalagem PET de $250 \mathrm{ml}$.

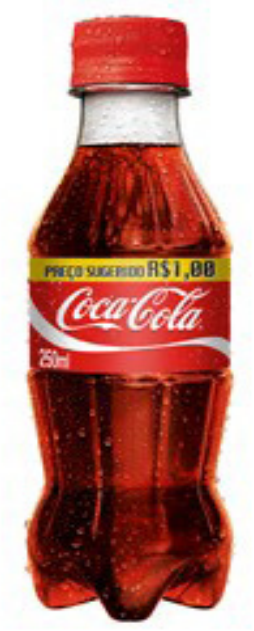

Fonte: Coca-Cola Mini Pet. Notícia de 01.04.2010. Portal Giro News. Disponível em: < http://www.gironews.com/ lancamentos/cocacola-mini-pet-6352/>. Acesso em 29.05.2015.

O principal objetivo desse novo produto estava em conquistar os consumidores de baixa renda por meio de um produto a um preço acessível em sua realidade orçamentária. Essa estratégia vai ao encontro do que observaram Chauvel e Mattos (2008), em um estudo que observou o comportamento de compra dos consumidores de baixa renda, em que as pesquisadoras colocam que para alcançar esse segmento, as empresas precisam desenvolver estratégias no sentido de conciliar os desejos dos consumidores com as limitações de um orçamento restrito. 
Rocha e Silva (2008), ao tratarem das restrições ao mercado para consumidores da base da pirâmide, sinalizam que outros tipos de restrições podem impactar suas escolhas. A restrição de tempo, decorrente do longo deslocamento de casa para o trabalho; o acúmulo de papéis sociais (sobretudo no caso das mulheres que trabalham fora e também são responsáveis pelas atividades dentro de casa); o baixo nível de escolaridade destes consumidores, que pode comprometer seu entendimento e sua consciência em relação a determinadas ofertas do mercado; dentre outros exemplos, ampliam a lista de possíveis restrições. Nesse sentido, seguindo a recomendação dos autores, este trabalho não se limitou a entender o consumidor de baixa renda como que restrito exclusivamente pelo recurso financeiro escasso, mas considerou todos os aspectos que poderiam afetar a sua decisão de consumo em relação ao lançamento do novo produto da Coca-Cola. Adicionalmente, buscouse entender como a estratégia do lançamento pela empresa Rio de Janeiro Refrescos poderia fomentar o consumo do refrigerante Coca-Cola, uma bebida de consumo não essencial, junto aos consumidores de baixa renda. Como se viu nesta pesquisa, em que pese o preço ter sido considerado um dos atrativos do novo produto, a adesão do público ao novo produto se pautou em razões para além do preço praticado para Coca-Cola Pet de $250 \mathrm{ml}$., tais como a diferenciação pela qualidade do refrigerante Coca-Cola, a força da marca Coca-Cola difundida a todos os segmentos de potenciais consumidores, a reputação do prestígio da bebida, o desejo de acesso ao refrigerante Coca-Cola pelos consumidores de baixa renda.

\section{0 impacto do lançamento do novo produto}

A expansão da classe média e a redução da desigualdade de renda são um fenômeno real que vem ocorrendo simultaneamente - e de forma acelerada - em muitas as economias emergentes. Essa expansão da classe média teve início há mais de uma década, ainda não atingiu seu pico e, deve-se estender por pelo menos mais dez anos. Um estudo realizado pelo banco de investimentos Goldman Sachs, intitulado "O meio que cresce", estima que até 2030 , dois bilhões de pessoas terão se juntado à classe média mundial (Friedlander et al., 2008). Com essa transformação, as pessoas passaram a poder comprar diversos bens, resultando em expansão na economia e, consequentemente, movimentando o mercado como um todo.

Nesse sentido, a RJR entendeu que considerar os segmentos de baixa renda representava uma decisão estratégica para empresa, tendo em vista o grande contingente de pessoas que o segmento representa. Soma-se a isso, a necessidade de promover a marca e ganhar espaço no mercado de bebidas ofertadas em pouca quantidade e a baixo preço, até então ocupados predominantemente pelos guaracopos, refrescos e caldos de cana.

Primeiramente, a embalagem de Coca-Cola Pet de $250 \mathrm{ml}$. foi lançada apenas no mercado carioca e apresentada aos canais varejistas em determinados pontos de venda, que atendiam bairros periféricos e comunidades de baixa renda. $O$ produto foi apresentado aos varejistas pelos representantes comerciais da empresa RJR, e com o apoio de materiais de comunicação.

No caso desta embalagem em particular foram desenvolvidos apenas materiais de comunicação para os pontos de venda, e foi feita uma extensa campanha de divulgação para a Força de Vendas nas matinais, equipe esta responsável em penetrar com o produto nos clientes (Gerente de Marketing da RJR).

Segundo a analista de marketing da RJR, a recepção tanto dos varejistas quanto dos consumidores foi positiva. Um gerente de ponto de vendas que foi selecionada para oferta o produto no momento do lançamento complementa:

Foi boa a recepção da Coca-Cola de $\mathrm{R} \$ 1,00$. O preço é bastante agradável aos clientes que compram desde que lançou [...] os clientes gostaram, falaram que foi uma boa invenção (Gerente de um minimercado no Rio de Janeiro).

Como consequência da recompra dos clientes, o estabelecimento comercial também passou a pedir e comprar mais do novo produto.

O volume de compras da Coca-Cola de garrafinha aumentou muito aqui ao longo do tempo (Gerente de um minimercado no Rio de Janeiro).

Foi além do esperado [os resultados do lançamento]. Hoje, por exemplo, a empresa não está conseguindo produzir na capacidade da demanda (Analista de Marketing da RJR).

As afirmações acima, tanto do gerente do ponto de venda quanto da analista de marketing da empresa RJR, sugerem que o novo produto foi muito bem recebido pelos consumidores que se desejava alcançar. Considerando o aumento do volume de compras, foram os próprios varejistas que sugeriam que a empresa fornecesse outros refrigerantes da marca, na mesma embalagem e preço. O gerente do minimercado (em entrevistas aos autores) comentou que os clientes perguntavam se, além da Coca-Cola, iria ter Coca-Cola Zero, Fanta ou Sprite. Segundo a analista de marketing da RJR (entrevista aos autores), que idealizou o projeto de lançamento do produto 
Coca-Cola na embalagem de $250 \mathrm{ml}$., essa resposta veio de praticamente todos os pontos de venda em que inicialmente se disponibilizou o produto.

Porém, segundo a analista de marketing da RJR (entrevista aos autores), apesar do resultado satisfatório e das solicitações do mercado, expandir o portfólio de sabores não está no plano de curto prazo da RJR por motivos de limitações de produção e, sobretudo, em função do perfil dos consumidores foco. Se apenas pelo sucesso do projeto, a embalagem fosse disponibilizada para outros canais com perfil diferente daqueles definidos para o lançamento, poderia acontecer de canibalizar outras embalagens, prejudicando a margem da empresa.

É importante destacar, ainda, que o lançamento deste novo produto teve resultados tão positivos para a empresa RJR e, também, para o sistema Coca-Cola Brasil, que em menos de dois anos outros fabricantes autorizados lançaram a embalagem para suas regiões de atuação. O objetivo desses outros fabricantes seria novamente de conquistar novos consumidores, mas as características do público-alvo podem variar, de acordo com as particularidades de cada região onde o produto foi lançado, tais como concorrentes, poder aquisitivo da população, entre outras. As notas divulgadas pela impressa exemplificam esse fato:

\footnotetext{
"Para consumo individual, no trânsito, no trabalho, na pausa para o lanche ou situações de deslocamento. Essa é a proposta que a Coca-Cola/Norsa faz ao lançar a embalagem Pet $250 \mathrm{ml}$. em Salvador e Feira de Santana do refrigerante mais consumido do mundo. Criada para possibilitar novas ocasiões de consumo, a nova embalagem chega a todos os supermercados e pontos de venda das cidades e chega ao consumidor final no valor $\mathrm{R} \$ 1,00$ com o benefício de caber na bolsa ou mochila". (Notícia Capital, 2011).

"A Coca-Cola FEMSA Brasil apresentou a nova embalagem de $250 \mathrm{ml}$. do refrigerante Coca-Cola: a Mini Pet. O produto está disponível nos principais pontos de venda nos estado de São Paulo. Criada para possibilitar novas ocasiões de consumo, o produto chega ao consumidor final ao valor de $\mathrm{R} \$ 1,00$. Entre as vantagens destacam-se a praticidade e rapidez para consumo e transporte do produto". (Giro News, 2010).
}

Os achados desse estudo mostram que para explorar o mercado de consumidores que ocupam a base da pirâmide socioeconômica, as empresas devem estar abertas, como sugerido por Prahalad (2005), a criar produtos e processos voltados especialmente para atender aos desejos e necessidades desse grupo de consumidores, por meio de soluções inovadoras, criativas e, sobretudo, criando estratégias de precificação dentro de suas condições financeiras. Em que pese a real possibilidade dos riscos envolvidos, a empresa Rio de Janeiro Refrescos procurou articular a qualidade da marca já experimentada e reconhecida no mercado (Brakus et al., 2009) a um preço acessível (Chauvel \& Mattos, 2008), desenvolvendo e lançando o produto Coca-Cola Pet $250 \mathrm{ml}$., com o objetivo de fornecer aos consumidores de menor poder aquisitivo um produto Coca-Cola que "cabe no bolso". A experiência bem-sucedida da empresa permitiu que fosse incluído em seu portfólio um produto capaz de enfrentar os principais concorrentes de bebidas não alcoólicas de baixo preço, além de alcançar um enorme grupo de consumidores que passaram a ter condições de consumir seu produto com maior regularidade.

Existem várias questões a serem conhecidas e aprofundadas entre os segmentos mais populares de consumidores (Barros \& Rocha, 2009). Os grandes centros urbanos possuem grupos de pessoas pertencentes às classes mais baixas, em geral residentes em comunidades e em bairros de áreas suburbanas, que possuem renda limitada e fortemente comprometida com necessidades mais básicas. Desse modo, a participação no mercado de consumo poderia aparecer como uma forma de inclusão social (Rocha \& Silva, 2008). O estudo de Araujo et al. (2013) mostrou que a restrição financeira alinhada à restrição ao consumo existente no segmento de baixa renda impõe a este grupo a necessidade de encontrar formas alternativas de saciar suas necessidades de consumo, optando por um substituto ou, por vezes, mudando o foco do consumo. Para Rocha e Silva (2008), a empresas que desenvolvem estratégias que facilitem o consumo desse grupo de consumidores teria um papel fundamental nesse processo de inclusão social por meio do consumo. Não se trata apenas de gerar o desejo de compra, mas também de prover meios para que o acesso ao consumo pela base da pirâmide seja possível.

Ainda assim, conforme sublinham Chauvel e Mattos (2008, p. 5), na prática, o fato de pertencerem a classes baixas limita as opções de consumo deste grupo. Apesar de ter havido um aumento de sua renda e de seu poder de compra, "não se pode perder de vista a superfície dura da vida da população de baixa renda, [...] na qual a escassez ainda é, [...], um elemento central para sua compreensão". Desse modo, apesar do fato de grande parte da população de baixa renda reconhecer que usufruir do mercado de consumo (Araujo et al., 2011) e desejar produtos de qualidade reconhecida, não se deve desconsiderar que alguns desses gastos, tais como o consumo de bebidas não alcoólicas, como o refrigerante, são considerados supérfluos - e logo não essenciais - no consumo desse grupo (Barreto \& Bochi, 2002). 
Nesse sentido, a iniciativa de Rio de Janeiro Refrescos ao incluir no mercado um produto com valor de troca compatível com o que as classes mais populares podem pagar, além de se beneficiar com um possível aumento o consumo do refrigerante Coca-Cola, a empresa abre caminho para viabilizar a inclusão e o acesso dos consumidores de baixa renda ao consumo de um produto desejado e de qualidade reconhecido no mercado, até então pouco acessível para uns ou de acessibilidade limitada para outros. Isso pôde ser evidenciado, segundo os entrevistados, pelo fato dos indivíduos se apropriaram do produto e o buscarem em outros pontos de vendas, além de demandaram por embalagens e preços similares a outros sabores da marca. Isso implica que acesso mais amplo ao mercado de consumo deve ser compreendido como desejado e, nesse sentido, deve ser compreendido também como inclusivo. Dessa forma, acreditar que o consumidor popular evita produtos de prestígio e abrem mão da qualidade para pagar por um produto mais acessível de qualidade inferior se revela um engano, tendo em vista que ao terem acesso a produtos de qualidade e de marca já reconhecida no mercado, os consumidores de baixa renda efetivamente se voltam a este consumo, demandando por novas possibilidades e acessos no mercado, como se viu na experiência bem-sucedida do lançamento da Coca-Cola Pet $250 \mathrm{ml}$. realizada no Brasil pela empresa Rio de Janeiro Refrescos.

\section{Considerações Finais}

Esse trabalho buscou investigar o caso do lançamento da embalagem de Coca-Cola Pet 250 mililitros (ml.) realizado pela empresa Rio de Janeiro Refrescos (RJR), buscando entender o comportamento do consumidor de baixa renda em relação ao novo produto, bem como perceber os impactos do lançamento do novo produto para os varejistas e para a própria empresa. A RJR identificou o potencial de compra dos consumidores de baixa renda ao observar a realidade do mercado de bebidas não alcoólicas do Rio de Janeiro, no qual os concorrentes diretos (outras marcas de refrigerantes) e indiretos (substitutos como refrescos, caldos de cana e guaracopos) alcançam grandes volumes de vendas.

Os pressupostos teóricos da pesquisa indicavam que havia uma relação direta entre o consumo de bens de marcas que indicam maior qualidade e o comportamento de consumo do brasileiro, incluindo o comportamento de compra dos consumidores brasileiros de baixa renda, conforme descrito na revisão da literatura. Não havia, no entanto, pesquisas realizadas no Brasil que mostrassem tal relação com o mercado de bebidas, muito menos um estudo considerando à classe social e o consumo de bebidas. Neste sentido, o estudo buscou avançar no conhecimento do comportamento do consumidor de baixa renda e nas relações deste consumidor com o mercado de alimentos, mais especificamente o mercado de bebidas não alcoólicas. $\mathrm{O}$ estudo contribui para que as empresas que ofertam no mercado produtos que podem ser de interesse de diferentes segmentos possam considerar incluir os consumidores de baixa renda e considerar o seu potencial de consumo. Isso é feito ao trazer a experiência do lançamento da CocaCola Pet $250 \mathrm{ml}$. e, assim, propor reflexões que ajudam a compreender o comportamento de consumo desse segmento.

Como se viu, a empresa começou a estudar a formulação de uma estratégia no nível da unidade de negócio, considerando as variáveis de escolhas dos segmentos de clientes e de nível relativo de preço. A partir do objetivo de alcançar os consumidores de baixa renda, optou-se por considerar a estratégia de diferenciação por preço, como sugerido por Tavares (2000). Assim como ensinado por Prahalad (2005), a capacidade de compra envolve a capacidade de criação de ofertas que sejam acessíveis à classe que se deseja alcançar. Considerando o orçamento limitado da população de baixa renda, uma alternativa é a criação de pacotes individuais e com preços mais acessíveis aos consumidores. Para atrair essa classe de consumidores, esta foi a solução encontrada pela RJR, que lançou em 2009 o produto Coca-Cola Pet $250 \mathrm{ml}$. para o estado do Rio de Janeiro ao preço sugerido de venda de $R$ \$ 1,00 (um real), buscando competir com outras bebidas não alcoólicas de preços mais acessíveis.

Segundo Chauvel e Mattos (2008), o fato de pertencerem a classes baixas limita as opções de consumo dos indivíduos. As observações feitas aos pesquisadores pelos entrevistados revelaram tal limitação. As restrições orçamentárias dos consumidores de baixa renda fazem com que estes optem por bebidas mais baratas nas compras mais cotidianas, enquanto os refrigerantes mais caros são compras em ocasiões mais específicas. Entretanto, o consumidor respondeu muito satisfatoriamente ao refrigerante de Coca-Cola em uma embalagem de plástico menor a um preço mais acessível, tendo em vista que o volume de compra dos varejistas dos pontos selecionados aumentou em função da alta de demanda gerada pela procura do produto. Além 
disso, dados aos bons resultados do produto junto aos consumidores, os varejistas apresentaram intenção de trabalhar com outros sabores da marca Coca-Cola na mesma embalagem diante das demandas trazidas pelos próprios consumidores. Outro dado que demonstra o resultado positivo da ideia, foi a rápida expansão da nova embalagem para novos pontos de venda e, em especial, para fabricantes autorizados do sistema Coca-Cola em outros Estados brasileiros.

O resultado revelou outros aspectos além do que se buscava originalmente. Observa-se, uma dose de satisfação em ter acesso a uma marca de refrigerante de maior prestígio no mercado a um preço mais adequado à sua realidade de consumo, mesmo que, por vezes, tal opção de compra represente a compra de quantidade menor de refrigerante consumida. A procura por outros refrigerantes da marca Coca-Cola no preço e tamanho da embalagem de Coca-Cola Pet $250 \mathrm{ml}$. pelos consumidores nos pontos de vendas sugere o interesse e a satisfação dos consumidores desse grupo pelo acesso aos refrigerantes da marca na nova embalagem de comercialização.

Pode-se entender o lançamento da Coca-Cola Pet 250 ml. realizado pela empresa Rio de Janeiro Refrescos direcionado a este grupo como positivo e satisfatório. Contudo, o presente estudo não identificou o uso direto de estratégias para diminuir os efeitos das restrições orçamentárias diante da necessidade de compras de quantidades maiores do refrigerante Coca-Cola pelos consumidores de baixa renda. Considerando que a Coca-Cola Pet $250 \mathrm{ml}$. atende somente ao consumo individual, seria interessante realizar novas pesquisas junto aos consumidores de baixa renda a fim de compreender mais profundamente sob que circunstâncias esse segmento pode demonstrar motivação para consumir os produtos de maior prestígio no mercado, como o refrigerante Coca-Cola, considerando a realidade de restrições orçamentárias a que são submetidos, diante da necessidade de compra em grandes quantidades. Além disso, a pesquisa não buscou compreender a percepção dos consumidores de classes de rendas maiores em relação à Coca-Cola Pet $250 \mathrm{ml}$. Recomenda-se o aprofundamento da investigação, no sentido de entender como é percebida a disponibilidade do produto por consumidores de outras faixas renda.

Este estudo possui limitações, pois se trata de um estudo de natureza qualitativa, não sendo possível a generalização empírica dos resultados. Contudo, a pesquisa contribui para a literatura de marketing e de estudos na base da pirâmide, complementando as pesquisas já existentes. O artigo evidencia a importância de tentar buscar compreender as demandas de mercado para atender melhor os consumidores, considerando suas diferentes realidades. Além disso, observou-se que a renovação do portfólio de produtos, quando adequados as necessidade de segmentos específicos, tende a conquistar novos consumidores, a aumentar a participação de mercado e, consequentemente, a rentabilidade da empresa.

\section{Referências Bỉbliográficas}

\section{Aaker, D.A. Marcas - Brand Equity: Gerenciando o valor das marcas. São Paulo: Negócio Editora, 1998.}

Afrebras Bebidas: Refrigerantes. Associação dos Fabricantes de Refrigerantes do Brasil (Afrebras). Disponível em: $<$ http://www.afrebras.org.br $>$. Dados de 2013. Acesso em 16. jul.2014.

Anderson, T. Exploding myths about Marketing to Ds and Es. Brand Strategy, v. 162, nº.1, 2002.

Araujo, F.F.; Rocha, A.; Chauvel, M.A.; \& Schulze, M.F. Meanings of leisure among young consumers of a Rio de Janeiro low-income community. Leisure Studies, v. 32, n.3, p. 319-332, 2013.

Araujo, F.F., \& Chauvel, M.A. Filmes franceses no mercado brasileiro - refletindo sobre as estratégias promocionais de uma distribuidora independente: um caso de ensino. Revista de Economia e Administração, v.13, n.1, p.115-142, 2014.

Araujo, F.F., \& Chauvel, M.A. Marketing de Cinema Francês no Brasil: Um estudo exploratório sobre as estratégias de promoção para o lançamento de filmes no mercado brasileiro. FACEF Pesquisa: Desenvolvimento e Gestão, v. 15, n. 3, 2012.

Araujo, F.F. de, Chauvel, M.A., \& Schulze, M.F. Percepções e Significados do Lazer do Jovem de Baixa Renda: Um Estudo Exploratório em uma Comunidade da Zona Sul Carioca. Anais do XXXV Encontro da ANPAD. Rio de Janeiro: Anpad, 2011.

Azevedo, P.F. Ato de Concentração n ${ }^{\circ}$. 08012.001383/2007-91. Conselho Administrativo de Defesa Econômica - CADE. Ministério da Justiça, fls. 1.639-1.692, 2008.

Barbosa, P.M.B.; Hor-Meyll, L.F.; \& Motta, P.C. O uso de celular pré-pago por consumidores de baixa renda. In: Rocha, A.M.C. da, \& Silva, J.F. da (Orgs.). 
Consumo na Base da Pirâmide: Estudos Brasileiros. Rio de Janeiro: Mauad X, 2009.

Barreto, F.;\& Bochi, R. Mercados Pouco Explorados: Descobrindo a Classe C. The Boston Consulting Group. Disponível em: < http:/ /www.bcg.com> . 2002. Acesso em 22.jul.2014.

Barros, C., \& Rocha, E. Lógica de Consumo em Grupos das Camadas Populares: Uma visão antropológica de significados culturais. Anais do XXXI Encontro da ANPAD. Rio de Janeiro: Anpad, 2007.

Barros, C. Consumo, Hierarquia e Mediação: Um estudo antropológico no universo das empregadas domésticas. Anais do XXX Encontro da ANPAD. Salvador: Anpad, 2006.

Brakus, J.J.; Schmitt, B.H.; \& Zarantonello, L. Brand experience: What is it? How is it measured? Does it affect loyalty? Journal of Marketing, v. 73, $\mathrm{n}^{\circ} .3$, p. 52-68, 2009.

Brown, S. Marketing Science in a post modern world: introduction to the special issue. European Journal of Marketing, v. 31 (3/4), p. 167-182, 1997.

Castilhos, R.B. Subindo o Morro: Consumo, posição social e distinção entre famílias e classes populares. Anais do XXXI Encontro da ANPAD. Rio de Janeiro: Anpad, 2007.

Chauvel, M.A., \& Mattos, M.P.A.Z. Consumidores de Baixa Renda: Uma revisão dos achados de estudos feitos no Brasil. Cadernos Ebape, vol. 6, n. 2, p. 1-16, 2008.

Clic RBS. Uma Coca-Cola para Cada Pessoa: Vonpar aposta em mais investimentos para reforçar presença do refrigerante. A Notícia. In: Portal Clic RBS. 2009. Disponível em: <http://www.clicrbs.com. $\mathrm{br} /$ anoticia/jsp/default2.jsp?uf $=2 \&$ local $=18 \&-$ source $=a 2590230 . x m l \&$ template $=4187$.dwt\&edition $=12774 \&$ section $=1616>$. Acesso em 01.jul.2014.

Coca-Cola Brasil. Portal do Sistema Coca-Cola

Brasil. Disponível em <http://www.cocacolabrasil. com.br>. Acesso 25.jul.2014.

D’Andrea, G.; Stengel, E.A.; \& Goebel-Krstelj, A. Crear valor para los consumidores emergentes. Harvard Business Review. Novembro: 95-101, 2003.

Duailibi, J.; \& Borsato, C. Ela empurra o crescimento. IPSOS. São Paulo, abr. 2008. Disponível em <http://www.ipsos.com.br>. Acesso em 25.ago.2013.
Friedlander, D.; Martins, I.; \& Moon, P. A nova classe média do Brasil. Revista Época. 20 (534), 2008, p.92-101.

Gaskell, G. Pesquisa Qualitativa com Texto Imagem e Som: Um Manual Prático. Petrópolis: Vozes, 2002.

Giovinazzo, R.A., \& Wright, T.C.J. O mercado e o desempenho das empresas focadas em bens populares no Brasil. Anais do VII SEMEAD. USP: São Paulo, 2004.

IBGE. Instituto Brasileiro de Geografia e Estatística. Pesquisa de Orçamentos Familiares - POF 20082009. Portal do Instituto Brasileiro de Geografia e Estatística - IBGE. Dezembro, 2010. Disponível em: <http://www.ibge.gov.br/home/presidencia/ noticias/noticia_

visualiza.php?id_noticia $=1648 \& i d \_p a g i n a=1>$. Acesso em 02.jul.2014.

IBOPE. Diante da estabilidade no consumo, setor de bebidas passa a investir mais em publicidade.

Portal Ibope. 2008. Disponível em: < http://www. ibope.com.br/calandraWeb/servlet/CalandraRedirect?temp $=5 \&$ proj $=$ PortalIBOPE\&pub $=$ T\&$\mathrm{db}=\mathrm{caldb} \& \mathrm{comp}=$ Noticias $\&$ docid $=4 \mathrm{~A} 42 \mathrm{~B} 1 \mathrm{E}-$ DAF223191832574060000A209>. Acesso em 14.jul.2014.

Giro News. Coca-Cola Mini Pet. Portal Giro News. Notícia de 01.04.2010. Disponível em:

$<$ http://www.gironews.com/lancamentos/cocacolamini-pet-6352/>. Acesso em 29.05.2015.

Keller, K.; Sternthal, B.; \& Tybout, A. Fazer diferença não basta. Revista Exame. São Paulo. Edição 779, p. 94-100, 2002.

Kelman, J.C.; Chauvel, M.A.; \& Lopes, R. G. How to Communicate with Low Income Consumers: a Qualitative Study on Supermarkets Ads. In: III Conference on Discourse, Communication and the Enterprise. Rio de Janeiro: Dicoen, 2005.

Mattar, F. N. Pesquisa de Marketing: metodologia, planejamento. $4^{\text {a }}$.ed. Vol. 1, São Paulo: Atlas, 1997.

Mattoso, C.Q.; \& Rocha, A. da. Significados associados às estratégias para solução de problemas financeiros dos consumidores pobres. Anais do XXIX Encontro da ANPAD. Brasília: Anpad, 2005.

McCracken, G. (1988). The long interview: Qualitative Research Methods Series, v.13, Newbury Park: Sage Publications. 
Nielsen Brasil. Vendas de bebidas e produtos perecíveis confirmam bom momento da economia brasileira. In: Portal Nielsen Brasil. 2010. Disponível em: <http://br.nielsen.com/news/vendas_bebidas_ pereciveis.shtml>. Acesso em 14.jul.2014.

Notícia Capital. Coca-Cola Mini Pet $250 \mathrm{ml}$ chega em Salvador e Feira de Santana. In: Portal de informação Noticia Capital. 2011. Disponível em: < http:/ / www. noticiacapital.com.br/index.php?option $=$ com_con tent $\&$ view $=$ article\&id $=22927$ : coca-cola- mini-pet 250-ml-chega-em-salvador $-\&$ catid $=98$ :propaganda- mercado\&Itemid=119> . Acesso em 01.ago.2013.

Oths, K.S.; Carolo, A.; \& Santos, J.E. Social Status and Food Preference in Southern Brazil. Ecology of Food and Nutrition, vol.42, p.303-324, 2003.

Prahalad, C.K. A Riqueza na Base da Pirâmide: Como erradicar a pobreza com o lucro. Porto Alegre: Bookman, 2005, 392 p.

Prahalad, C.K., \& Lieberthal, K. The End of Corporate Imperialism. Harvard Business Review, vol. 81, issue 8, p. 109-117, 2003.

Ponchio, M.C.; \& Aranha, F. Necessidades, vontades e desejos: a influência do materialismo sobre a dívida de consumo dos paulistanos de baixa renda. Anais do XXXI Encontro da ANPAD. Rio de Janeiro: Anpad, 2007.

Rede Bahia. Consumidores de Baixa Renda: conhecendo um pouco seu comportamento de compra. In: Estudo de mercado - Rede Bahia de Televisão. 2005. Disponível em: <http://ibahia. globo.com/tvbahia/comercial/pdf/renda.pdf $>$. Acesso em 02.jul.2012.

RJR. Portal RJR - Rio de Janeiro Refrescos. Disponível em: <http://www.rjrefrescos.com.br>. Acesso em 25.jul.2014.

Rocha, A. da; \& Silva, J.F. da. Inclusão Social e Marketing na Base da Pirâmide: Uma Agenda de Pesquisa. RAE-Revista de Administração de Empresas Eletrônica, v. 7, n. 2, 2008.

Silva, H.; \& Parente, J. 0. O mercado de baixa renda em São Paulo: um estudo de segmentação baseado no orçamento familiar. Anais do XXXI Encontro da ANPAD. Rio de Janeiro: Anpad, 2007.

Silva, M.J.S. A propaganda em televisão criando hábitos de consumo em população de baixa renda. Intercom, 2005. Disponível em: <http://intercom. org.br/papers/nacionais/2005/resumos/R1969-1. pdf>. Acesso em 19.mar.2014.

Tavares, M.C. Gestão Estratégica. São Paulo: Editora Atlas, 2000.

Veloso, C.A. Competitividade e Inovação na Indústria de Refrigerantes no Mercado Brasileiro. Trabalho de Conclusão de Curso. UNICAP. Pernambuco. 2004. Disponível em: <http://www. unicap.br/ccs/20041/monog_carolineveloso.pdf>. Acesso em 14.jul.2014.

Yin, R.K. Estudo de caso: planejamento e método.

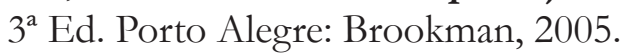

